\title{
Analisis Proses Bisnis Pengemasan Semen Menggunakan 7 Tools dan 11 Improvements Patterns
}

\author{
Sari Setyaningsih*, Nur Kholifathin Nadhiroh, Renny Sari Dewi \\ Sistem Informasi, Fakultas Teknologi Informasi dan Kreatif, Universitas Internasional Semen \\ Indonesia (UISI), Kompleks PT. Semen Indonesia (Persero) Tbk, \\ Jl. Veteran, Kb. Dalem, Sidomoro, Kebomas, Gresik, Jawa Timur 61122 \\ *e-mail: sari.setyaningsih17@student.uisi.ac.id
}

(received: 17 Desember 2020, revised: 26 Desember 2020, accepted: 27 Desember 2020)

\begin{abstract}
Abstrak
Menurut Direktur Utama Semen Indonesia Group, terdapat 19 perusahaan semen yang bermain di tahun 2020 ini, artinya terdapat kenaikan persaingan bisnis semen dibandingkan tahun 2015 yang hanya 7 perusahaan. Salah satu cara memenangkan persaingan ini yaitu dengan memahami proses bisnis, analisis kualitas, dan pengembangan proses bisnis. Penelitian ini bertujuan untuk menhasilkan saran yang dapat meningkatkan kualitas release semen dengan menggunakan metode 7 tools quality dan 11 improvement patterns. Objek penelitian yang digunakan ialah salah satu divisi packer pada salah satu plant di PT. XYZ. PT. XYZ sendiri merupakan salah satu produsen semen di Indonesia yang saat ini turut barmain pada pasar produksi semen. Data yang digunakan pada penelitian ini merupakan data primer yang didapatkan melalui pengamatan lapangan dan wawancara selama bulan Juli 2020 dan data sekunder yang didapatkan dari staff divisi packer. Analisis ini dapat digunakan untuk mengakomodir kebutuhan perusahaan untuk mengetahui masalah proses bisnis di salah satu divisi packer PT.XYZ agar perusahaan bisa mendapatkan saran untuk meningkatkan proses bisnis yang ada.
\end{abstract}

Kata Kunci: analisis proses bisnis, 7 tools, 11 improvement patterns

\begin{abstract}
According to the Managing Director of the Semen Indonesia Group, there are 19 cement companies playing in 2020, meaning that there is an increase in competition in the cement business compared to 2015 which only 7 companies. One way to win this competition is by understanding business processes, quality analysis, and business process development. This study aims to produce suggestions that can improve the quality of the cement release using the 7 quality tools and 11 improvement patterns. The object of research used is one of the packer divisions at one of the plants at PT. XYZ. PT. XYZ itself is one of the cement producers in Indonesia which is currently playing in the cement production market. The data used in this study are primary data obtained through field observations and interviews during July 2020 and secondary data obtained from the packer division staff. This analysis can be used to accommodate the company's needs to find out business process problems in one of the packer divisions of PT. XYZ so that the company can get suggestions for improving existing business processes.
\end{abstract}

Keywords: business process analysis, 7 tools, 11 improvement patterns

\section{Pendahuluan}

PT.XYZ merupakan salah satu perusahaan manufaktur yang bergerak pada produksi semen di Indonesia yang saat ini tengah mengalami tantangan dan persaingan dalam dunia industri persemenan. Hal ini sejalan dengan adanya 19 perusahaan semen yang bermain di tahun 2020, yang mengindikasikan adanya kenaikan persaingan bisnis dibandingkan tahun 2015 yang awalnya hanya ada 7 perusahaan semen di Indonesia [1]. Hal ini didukung oleh fakta bahwa setiap perusahaan mengupayakan peningkatan mutu, produktivitas, dan mempertahankan kualitas produk untuk meningkatkan daya saingnya [2]. 
Berdasarkan data yang didapatkan oleh peneliti pada bulan Juli 2020 terdapat 2.532.200 semen yang release dan 6.761 bag semen yang pecah di divisi packer satu plant di PT.XYZ. Dalam bisnis persemenan jumlah release semen yang sesuai dengan plan order release menjadi salah satu hal yang sangat penting terutama dalam proses pengemasan semen [3]. Seperti halnya [4], proses bisnis pengemasan semen juga memerlukan analisis dan evaluasi proses bisnis yang nantinya akan membantu dalam peningkatan daya saing perusahaan.

Penelitian ini bertujuan untuk mencari saran perbaikan proses untuk mengatasi masalah pada divisi packer dengan menggunakan metode 11 improvement patterns yang dipopulerkan oleh Michael Rosemann [5]. Untuk memenuhi tujuan tersebut analsisis dimulai dengan proses identifikasi untuk mendapatkan arsitektur proses yang ada, value chain analysis, permodelan BPMN, 7 tools analysis dengan fishbone diagram, check sheet, pareto, dan scatterplot. Harapannya, dengan analisis ini dapat mengakomodir kebutuhan PT.XYZ untuk mengetahui masalah yang ada di salah satu divisinya sehingga mampu meningkatkan proses bisnis yang berguna dalam peningkatan kualitas pengemasan produknya sehingga bisa menjadi perbaikan proses bisnis di masa mendatang.

\section{Tinjauan Literatur}

Business Process Modelling (BPM) merupakan diagram yang bermanfaat untuk memudahkan pemahaman alur proses secara terintegrasi [6]. BPM (BPM Lifecycle) dimulai dari proses identifikasi, proses discovery, proses analysis, proses redesign, proses implementasi, dan proses monitoring and controlling sesuai dengan Gambar 1.

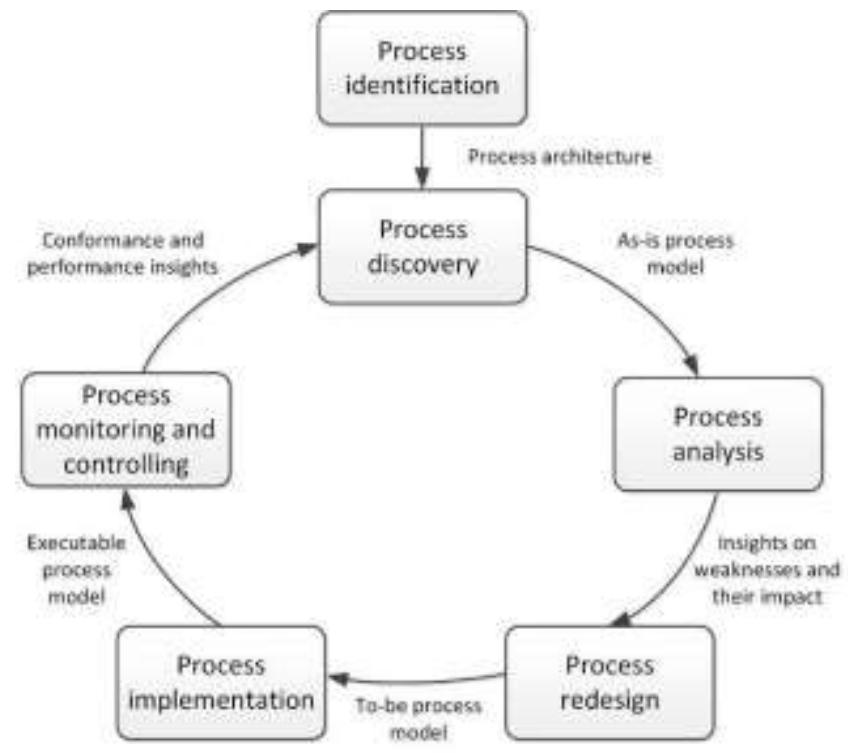

Gambar 1. BPM Lifecycle

Penelitian ini tidak melewati semua tahapan pada BPM Lifecycle dan hanya menempuh tiga tahapan berupa proses identifikasi, proses discovery, dan proses analysis sesuai deskripsi di bawah ini:

\section{Process Identification}

Hasil dari proses identifikasi berupa arsitektur proses yang menggambarkan management process, core process, support process, partner, dan stakeholder yang ada[7]. Value chain juga ditambahkan untuk menggambarkan rantai nilai pada salah satu proses yang terdapat dalam core process. Value chain analysis ialah proses pengidentifikasian kegiatan pada perusahaan dengan melihat kegiatan yang ada di organisasi[8]. 


\section{Process Discovery}

Pada tahap kedua ini menggunakan permodelan BPMN untuk menggambarkan proses bisnis yang ada di divisi packer. BPMN sendiri ialah suatu pemodelan grafis untuk memodelkan proses bisnis pada sebuah organisasi [9]. Setelah permodelan BPMN dilanjutkan dengan analisis Value Added.

\section{Process Analysis}

Tahap selanjutnya yaitu mengidentifikasi masalah dengan menggunakan 7 tools quality yang digunakan untuk menganalisis proses [10]. Pada umumnya, 7 tools quality yang paling umum digunakan ialah pareto diagram, cause and effect diagram, histogram, control charts, schatter diagram, grafik, dan check sheet [11]. Setelah mendapatkan hasil analisa proses dilanjutkan dengan pemberian saran terkait perbaikan proses bisnis (business process improvement) untuk mengatasi permasalahan [12], dengan menggunakan 11 improvement patterns. Perbaikan proses bisnis merupakan prioritas untuk perusahaan karena selalu terdapat peningkatan proses bisnis dari hulu ke hilir [13]. Dalam analisis masalah pengemasan semen ini hanya menggunakan cause and effect diagram (fishbone), check sheet, pareto chart, dan scatter diagram dari 7 tools quality, kemudian untuk sarannya menggunakan integration, improve, dan replace dari 11 improvement patterns.

\section{Metode Penelitian}

\subsection{Justifikasi Studi Kasus}

Subjek studi kasus merupakan divisi pengemansan (packer) pada salah satu perusahaan semen terbesar di Indonesia. Penentuan utama studi kasus berdasarkan alasan pengelola belum pernah menganalisis proses bisnis saat ini sehingga pengelola tidak dapat menganalisis risiko dalam rangka mitigasi risiko. Studi kasus PT.XYZ berlokasi di Jawa Timur dengan kapasitas produksi semen 15 juta ton per tahun.

\subsection{Pengumpulan Data}

Data pada penelitian ini didapatkan dari studi literatur, pengamatan aktivitas bisnis di divisi pengemasan salah satu plant di PT.XYZ, dan wawancara staff yang bekerja disana. Terdapat data primer dan sekunder yang menunjang penelitian ini. Data primer didapatkan langsung dengan wawancara dan observasi, sedangkan data sekunder didapatkan dari data yang sudah ada di divisi pengemasan.

\subsection{Alur Penelitian}

Alur penelitian ini dimulai dengan studi literatur untuk memberikan wawasan terkait subjek dan objek penelitian melalui literatur baik itu buku, maupun jurnal [14]. Langkah kedua yaitu dengan wawancara staff divisi packer dan mengumpulkan data release serta pecah kantong pada bulan Juli 2020. Proses selanjutnya yaitu identification, discovery, dan analysis sesuai dengan BPM Lifecycle sebagaimana jurnal [15]. Proses terakhir yaitu pemberian saran pengembangan dan perbaikan proses bisnis untuk memberikan rekomendasi dan perbaikan kinerja [16].

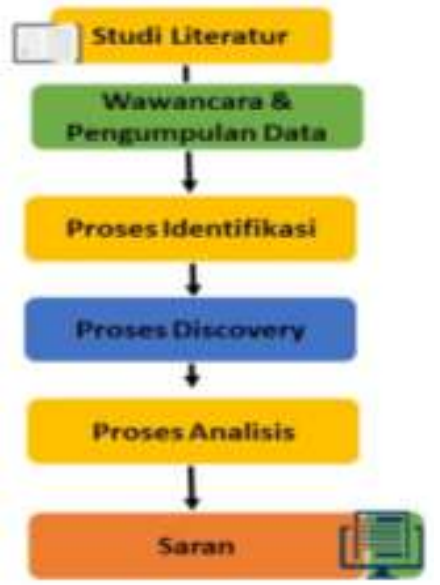

Gambar 2. Alur Penelitian 


\section{Hasil dan Pembahasan}

\subsection{Proses Identifikasi}

Hasil dalam identifikasi ini yaitu proses arsitektur di divisi packer PT.XYZ beserta value chain di divisi tersebut.

\subsubsection{Proses Arsitektur}

Pada proses arsitektur ini mendefinisikan proses yang ada di organisasi [17], terdapat lima (5) bagian dalam proses arsitektur ini yaitu management proses (proses manajerial), core process (proses bisnis inti), support proses (proses bisnis pendukung), partner, dan stakeholder di divisi packer PT.XYZ.

\begin{tabular}{|l|}
\hline \multicolumn{1}{|c|}{ Partner } \\
\hline $\begin{array}{l}\text { Seksi PMP } \\
\text { (Pemeliharaan } \\
\text { Mesin Packer) }\end{array}$ \\
\hline Seksi Finish Mill \\
\hline Seksi Shipping \\
\hline $\begin{array}{l}\text { Seksi PLIP } \\
\text { (Pemeliharaan } \\
\text { Listrik } \\
\text { Instrumen } \\
\text { Packer) }\end{array}$ \\
\hline \\
\hline Sub-Kontraktor \\
\hline
\end{tabular}
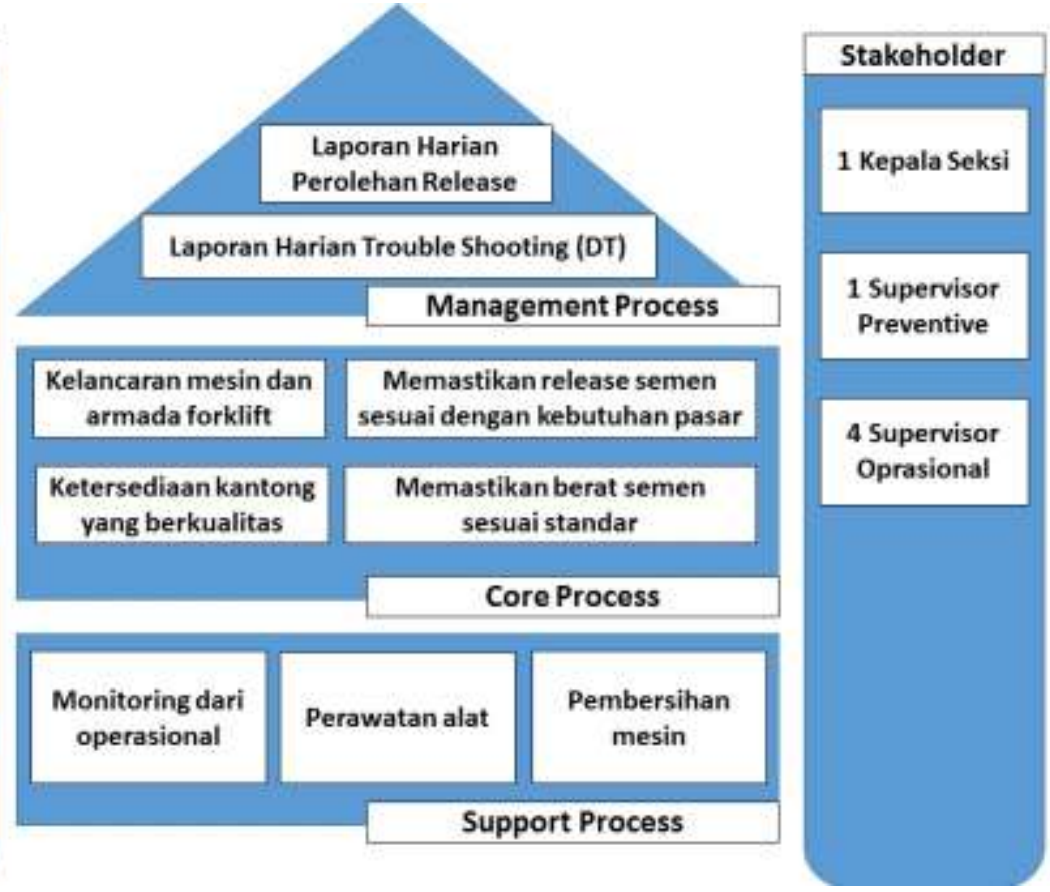

(Sumber: Diolah oleh peneliti, 2020)

\section{Gambar 3. Proses Arsitektur}

\subsubsection{Value Chain}

Value chain ini digunakan untuk mengidentifikasi proses "memastikan release semen sesuai kebutuhan pasar" pada core proses.

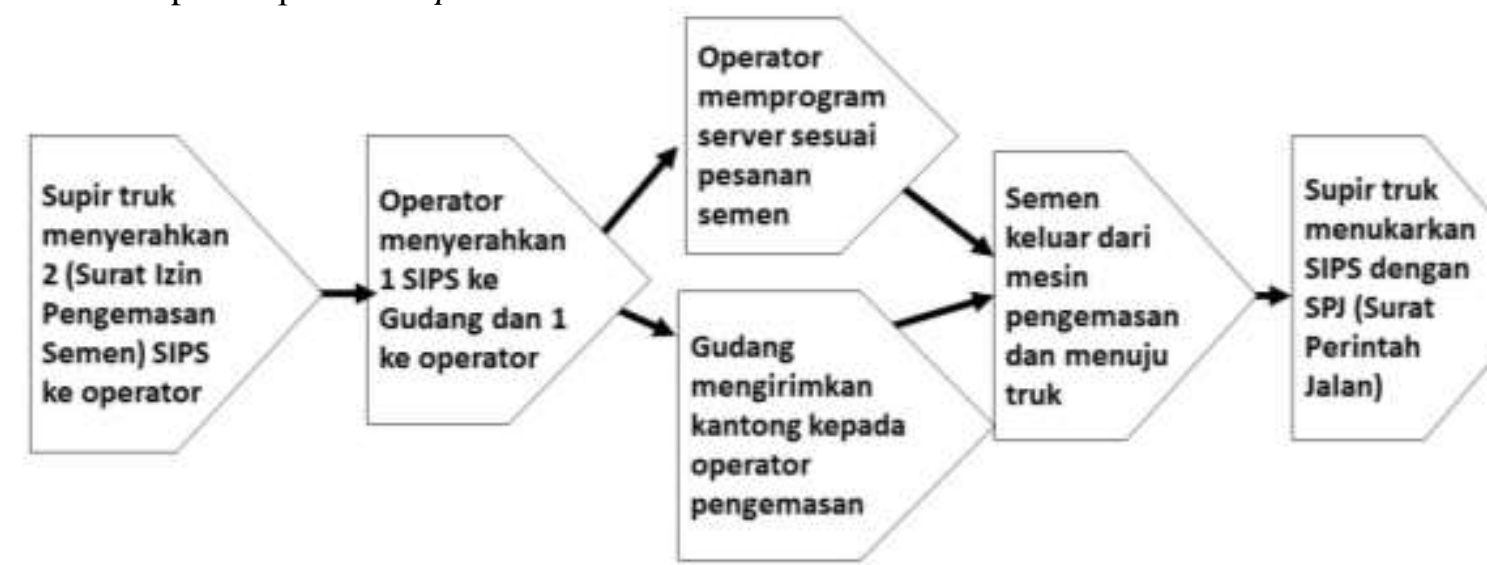

(Sumber: Diolah oleh peneliti, 2020)

\section{Gambar 4. Value Chain}




\subsection{Discovery Process}

Pada proses discovery ini menggambarkan proses bisnis yang ada di divisi pengemasan dengan menggunakan Business Process Model and Notation (BPMN). Penggambaran proses bisnis ini disesuaikan dengan stakeholder yang ada.

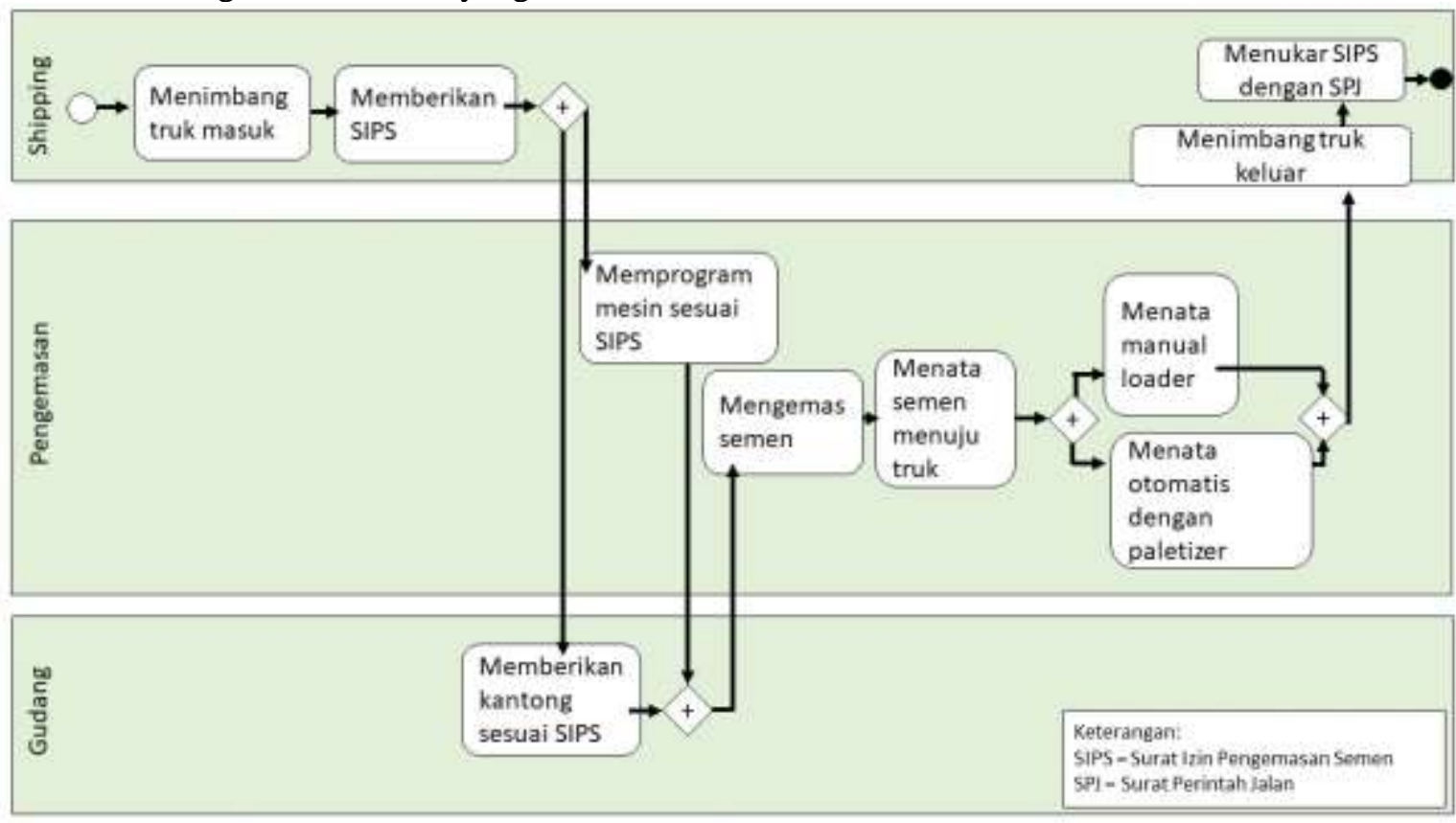

(Sumber: Diolah oleh peneliti, 2020)

\section{Gambar. 5 BPMN}

Analisis selanjutnya yaitu Value Added Analysis untuk mencari proses apa yang bernilai atau Value Added (VA) dan membedakannya dengan waste atau Non-Value Added (NVA), serta Business Value Added (BVA) yang diperlukan atau berguna supaya bisnis berjalan lancar.

Tabel 1. Value Added Analysis

\begin{tabular}{lll}
\hline \multicolumn{1}{c}{ Step } & \multicolumn{1}{c}{ Performer } & Classification \\
\hline Menimbang truk masuk & Shipping & BVA \\
Meminta SIPS pengisian semen curah & Operator silo packer & BVA \\
Meminta 2 SIPS untuk gudang dan operator & Operator & BVA \\
$\begin{array}{l}\text { Mensetting server roto packer } \\
\text { Start atau stop mesin packer lewat desktop Claudius }\end{array}$ & Operator & Operasional \\
$\begin{array}{l}\text { Peters } \\
\text { Mengisi semen curah }\end{array}$ & BVA \\
Memproses pengantongan semen & Operator silo packer & BVA \\
Memastikan semen berjalan di belt conveyor & Operator & BVA \\
dengan lancar & Operator & NVA \\
Menata semen secara manual ke truk & & \\
Menata semen secara otomatis mengunakan & Loader & VA \\
paletizer & Loader & VA \\
Menimbang truk yang memuat semen & & \\
Memberikan DPU saat berat tidak sesuai & Shipping & VA \\
Menambah semen ke truk & Shipping & BVA \\
Memuat ulang semen dengan yang baru Menukar & Operator silo packer & VA \\
SIPS dengan SPJ saat berat sesuai & Loader & VA \\
Memantau pendistribusian semen ke pelanggan & Shipping & BVA \\
\hline
\end{tabular}

(Sumber: Diolah oleh peneliti, 2020) 
Waste proses yang bisa dihilangkan yaitu saat operator memastikan semen berjalan di belt conveyor dengan lancar. Hal ini dapat diganti dengan pemasangan sensor di belt conveyor yang memantau berjalananya semen.

\subsection{Analysis Process}

Analisis ini untuk mendapatkan pendekatan kualitatif yang didapatkan dari fishbone (cause and effect diagram) dan pendekatan kuantitatif pada analisis jumlah gangguan, pareto, serta scatterplot.

\subsubsection{Tools Quality}

Fishbone (Cause and Effect)

Analisis ini untuk menjawab terkait masalah yang terjadi pada pengemasan semen di divisi packer salah satu plant di PT.XYZ. Karena PT.XYZ merupakan perusahaan manufaktur maka kategori yang digunakan ialah 6M (Machine, Method, Material, Mother Nature, Measurement, Man Power)

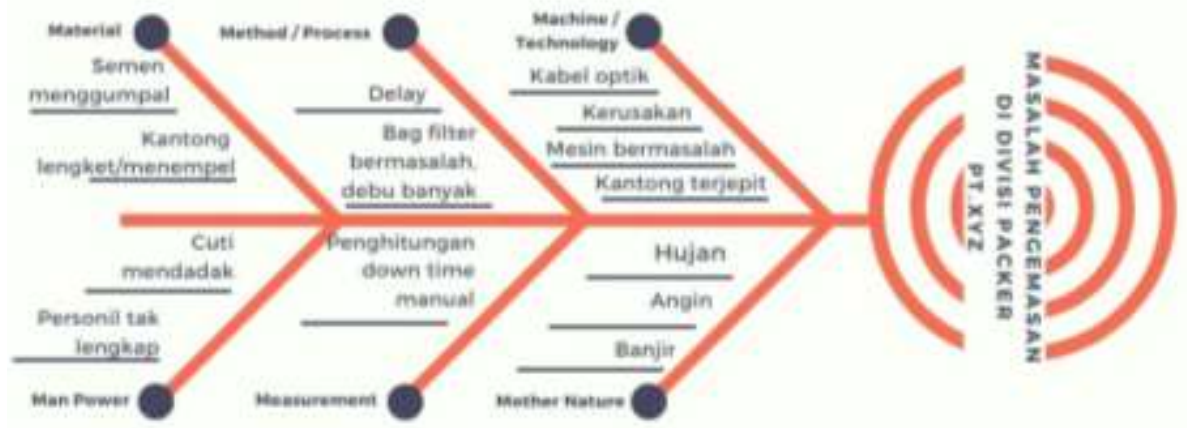

Gambar 6. Fishbone Diagram

(Sumber: Diolah oleh peneliti, 2020)

\section{Downtime Table}

Tabel ini menampilkan jumlah release bag kemasan $40 \mathrm{~kg}$, jumlah downtime dan gangguan, serta jumlah pecah bag kemasan $40 \mathrm{~kg}$ pada bulan Juli 2020.

Tabel 2 Jumlah Release, Pecah Bag, dan Downtime Pengemasan Semen 40 kg

\begin{tabular}{|c|c|c|c|c|c|c|c|c|c|c|c|c|c|}
\hline \multirow[b]{2}{*}{ Juli 2020} & \multirow{2}{*}{$\begin{array}{l}\text { Jumlah } \\
\text { Release } \\
\text { (bag) }\end{array}$} & \multicolumn{7}{|c|}{ Jenis Gangguan (mnt) } & \multicolumn{3}{|c|}{ Down Time(mnt) } & \multirow{2}{*}{$\begin{array}{l}\text { Jml. DT \& } \\
\text { Gangguan }\end{array}$} & \multirow{2}{*}{$\begin{array}{l}\text { Jumlah } \\
\text { Pecah } \\
\text { (bag) }\end{array}$} \\
\hline & & Truck & $\begin{array}{l}\text { Operator } \\
\text { SBG }\end{array}$ & \begin{tabular}{|l} 
Loader \\
SBG
\end{tabular} & Paletizer & Kantong & $\begin{array}{l}\text { Stock } \\
\text { Semen }\end{array}$ & $\begin{array}{l}\text { Operasi } \\
\text { onal }\end{array}$ & $\begin{array}{l}\text { Opera } \\
\text { si }\end{array}$ & \begin{tabular}{|l|} 
Meka \\
nik
\end{tabular} & $\begin{array}{l}\text { Elektri } \\
\text { kal }\end{array}$ & & \\
\hline DTAL & 2532200 & 19413 & 4402 & 844 & 4419 & 4950 & 1082 & 690 & 1908 & 7885 & 15277 & 60870 & 6761 \\
\hline
\end{tabular}

(Sumber: PT.XYZ, 2020)

\section{Pareto Chart}

Dari Tabel 2 di atas dapat tergambarkan downtime teratas sesuai pada gambar diagram pareto di bawah ini.

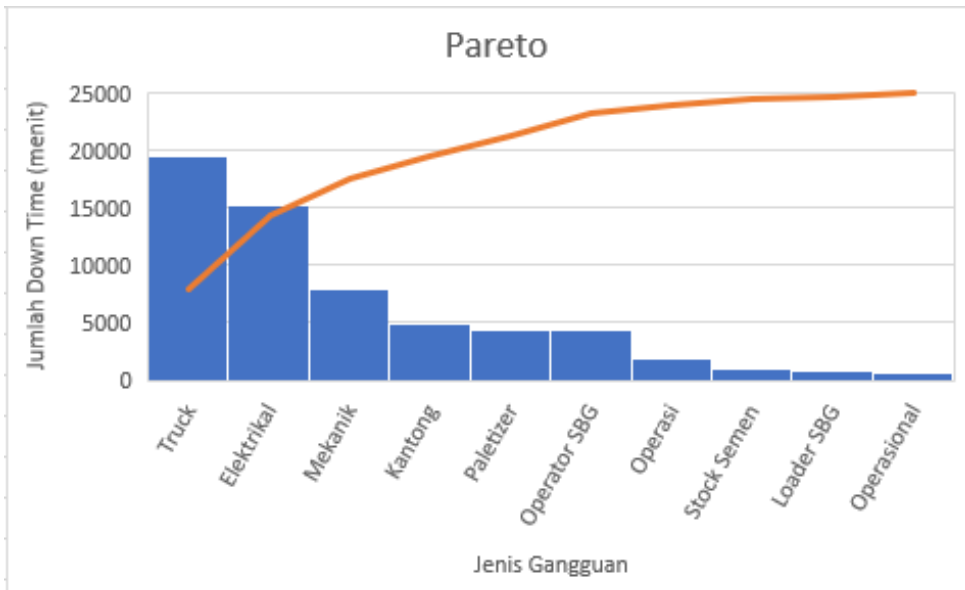

(Sumber: Diolah oleh peneliti, 2020)

Gambar 7. Pareto Diagram 


\section{Scatterplot}

Analisis ini untuk mengetahui keterkaitan antara 2 (dua) variabel. Analisi awal yaitu untuk mencari adakah hubungan antara release semen dan bag yang pecah pada kemasan $40 \mathrm{~kg}$. Dari scatterplot Gambar 7 dapat disimpulkan bahwa semakin banyaknya release semen mempengaruhi pecah kantong.

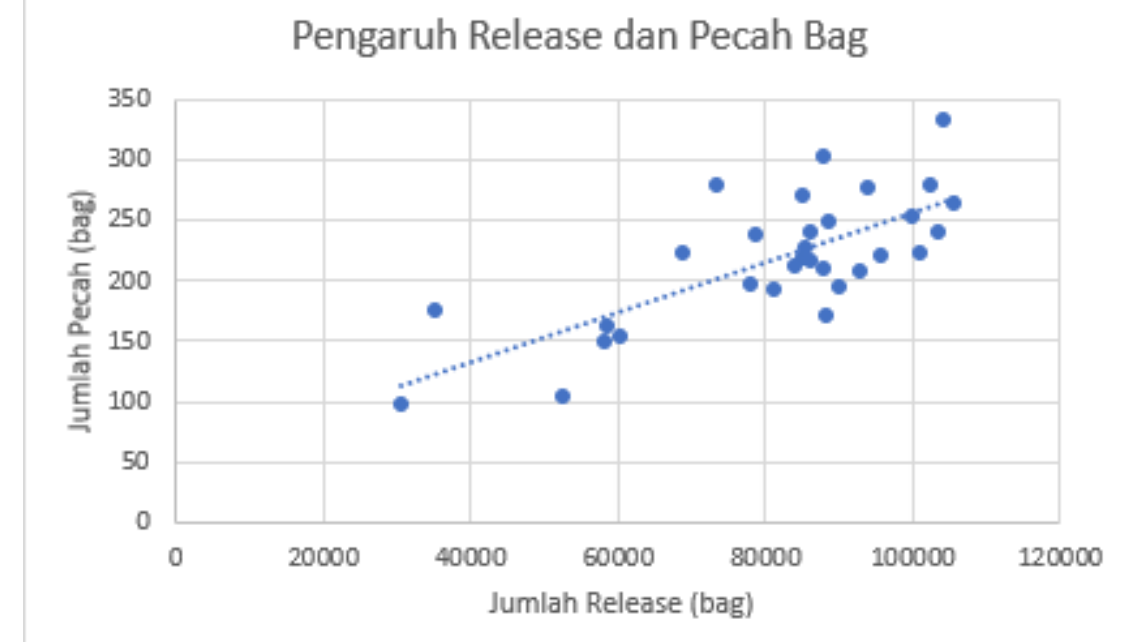

(Sumber: Diolah oleh peneliti, 2020)

Gambar 7. Scatterplot Release dan Pecah Bag

Analisis scatterplot yang kedua untuk mencari apakah massing - masing gangguan dan downtime mempengaruhi pecah kantong semen kemasan $40 \mathrm{~kg}$.
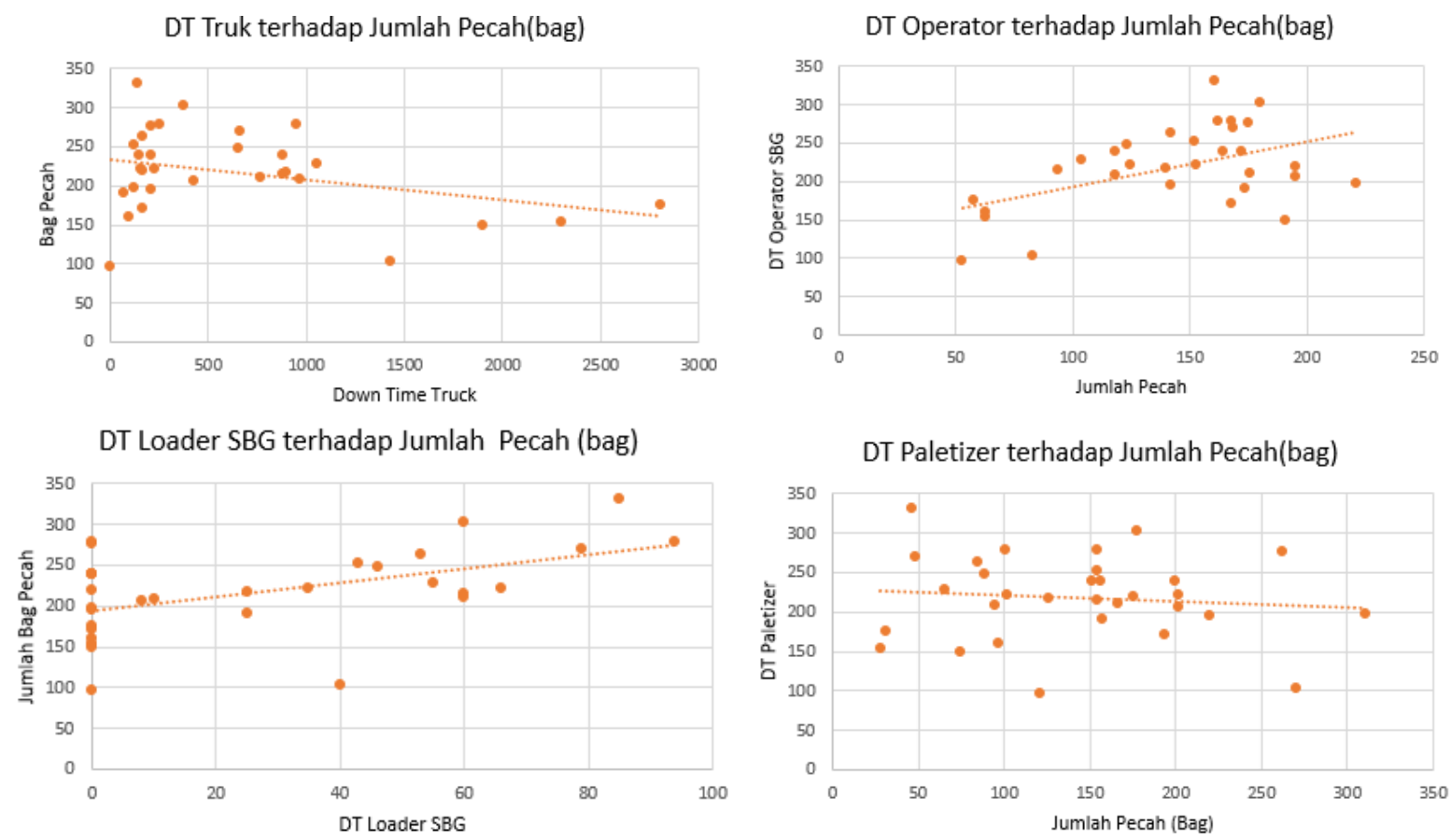

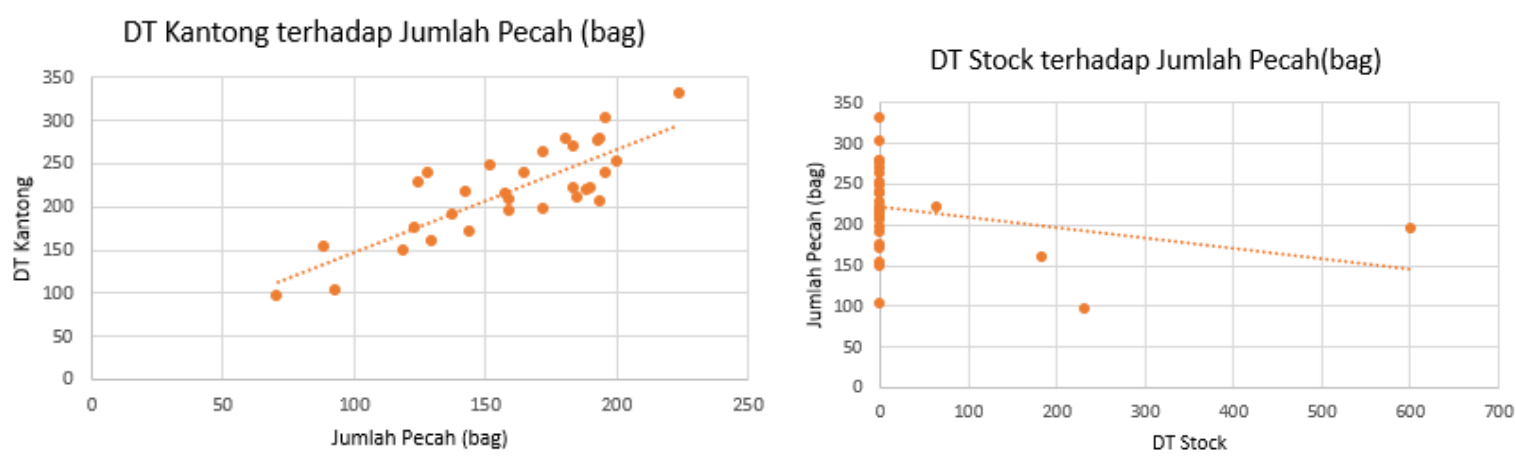

DT Operasional terhadap Jumlah Pecah(bag)

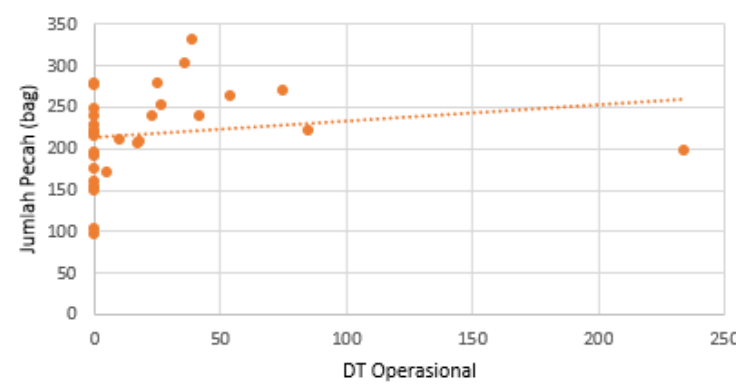

DT Operasi terhadap Jumlah Pecah(bag)

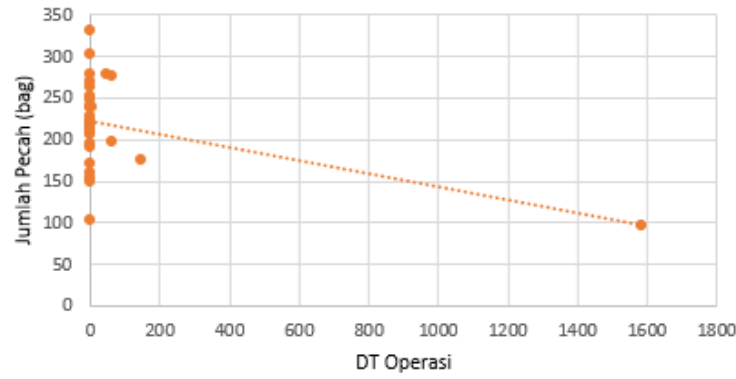

DT Elektrikal terhadap Jumlah Pecah(bag)

DT Mekanik terhadap Jumlah Pecah(bag)
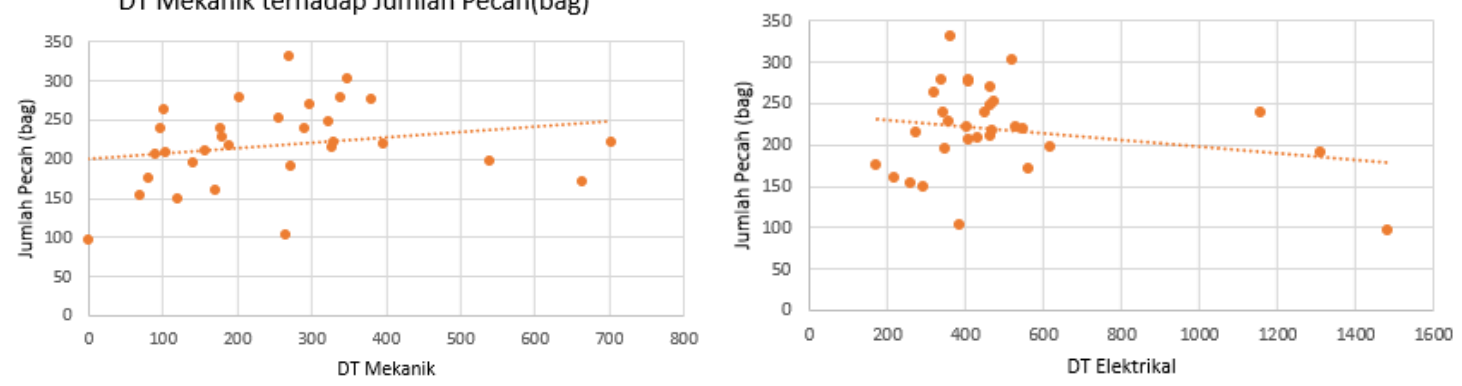

Gambar 8. Downtime, Gangguan, dan Pecah Bag

(Sumber: Diolah oleh peneliti, 2020)

Pada Tabel 3 ini merangkum analisis scatterplot kedua terkait downtime dan gangguan apa saja yang mempengaruhi pecahnya kantong semen $40 \mathrm{~kg}$.

Tabel 3. Downtime dan Gangguan yang Mempengaruhi Pecah Kantong (Bag)

\begin{tabular}{cc}
\hline Mempengaruhi Pecah Kantong & Tidak Mempengaruhi Pecah Kantong \\
\hline Operator SBG & Truk \\
Loader SBG & Paletizer \\
Kantong & Stok \\
Operasional & Operasi \\
Mekanik & Elektrikal \\
\hline
\end{tabular}

(Sumber: Diolah oleh peneliti, 2020)

\subsubsection{Improvement Patterns}

\section{Integration}

Dalam analisis fishbone ditemukan masalah pencatatan downtime dilakukan secara manual, hal ini menyebabkan operasional divisi pengemasan perlu melakukan pengerjaan ulang. Sehingga diperlukan proses integrasi antara proses operator mencatat manual downtime dengan operasional CCR mengecek laporan diintegrasikan menjadi operasional CCR mengecek di sistem. 


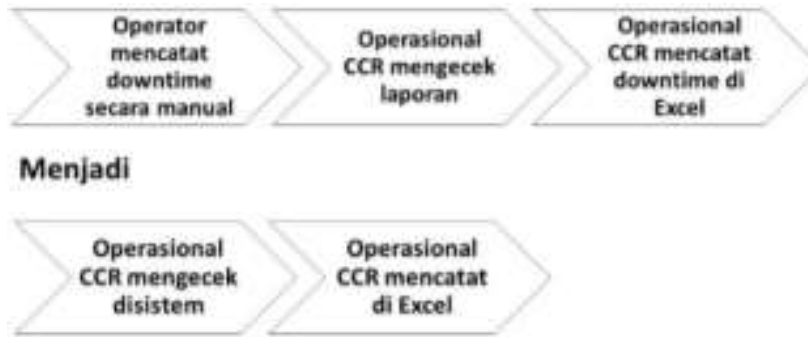

(Sumber: Diolah oleh peneliti,2020)

Improve

Gambar 9. Integration

Downtime pada kantong termasuk 5 masalah tertinggi berdasarkan data release dan downtime bulan Juli, salah satu penyebabnya bisa dikarenakan operator perlu waktu untuk memberikan Surat Izin Pengemasan Semen (SIPS) kepada gudang. Hal ini bisa diperbaiki dengan pengunaan teknologi telephone atau HT untuk menghubungi gudang, sehingga operator tidak perlu berjalan mengantar SIPS.

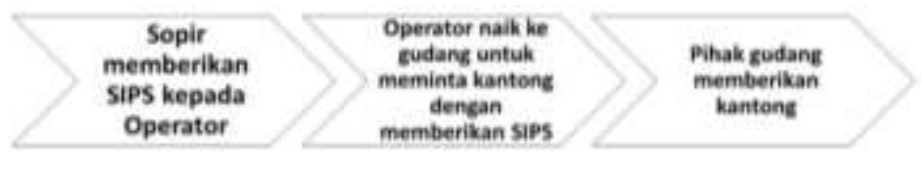

\section{Menjadi}

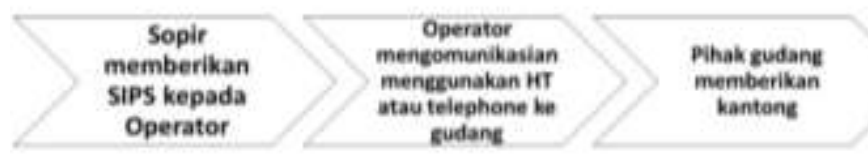

Gambar 10. Improve

(Sumber: Diolah oleh peneliti,2020)

\section{Replace}

Downtime truk merupakan downtime yang tertinggi dan salah satu masalah yang menyebabkan delay adalah proses penataan semen ke truk yang belum semuanya menggunakan palletizer. Proses penataan manual membutuhkan waktu yang lama.
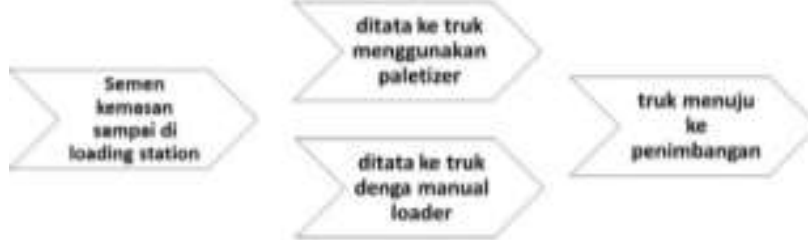

Menjadi
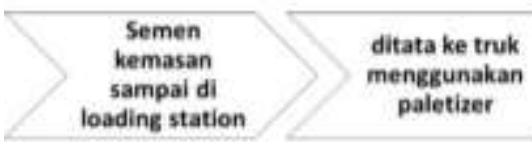

truk menuju ke penimbangan

(Sumber: Diolah oleh peneliti,2020)

\section{Gambar 11. Replace}

\section{Kesimpulan}

Dari hasil analisis di atas yang berupa permodelan proses, analisis 7 tools, dan 11 improvement patterns didapatkan hasil bahwa dalam proses identifikasi terdapat 4 proses inti (core process) dan terdapat waste proses dari value added analysis. Kemudian pada analisis proses dengan 7 tools quality masalah pengemasan pada divisi ini dikategorikan menjadi 6M yaitu Machine, Method, Material, Mother Nature, Measurement, dan Man Power. Untuk analisa kuantitatif peneliti menggunakan data yang diperoleh dari staff divisi packer PT.XYZ untuk mencari downtime teratas yang menyebabkan gangguan pada proses pengemasan. Selanjutnya pada analisis scatterplot didapatkan keterkaitan 
antara pecahnya kantong dengan jumlah release dan downtime. Saran untuk pengembangan proses bisnis yang ada yaitu dari segi integration dengan pencatatan downtime secara langsung oleh operasional tanpa menunggu catatan dari operator. Saran kedua yaitu improve dengan menggunakan teknologi telephone atau HT untuk menghubungi gudang kantong. Saran terakhir yaitu dengan melakukan replace dengan penggunaan palletizer di semua proses penataan semen di truk.

\section{Referensi}

[1] M. C. Anwar, "BUMN Semen Curhat: Produksi Lebih, Asing Bangun Pabrik Terus," 18 Februari, 2020. https://www.cnbcindonesia.com/news/20200218192341-4-138838/bumnsemen-curhat-produksi-lebih-asing-bangun-pabrik-terus.

[2] R. N. Ghifari, A. Suharsono, and N. Suhermi, "Analisis Pengendalian Kualitas pada Proses Pengemasan Portland Pozzolan Cement (PPC) di PT Semen Gresik (Persero), Tbk. Pabrik Tuban," J. Sains dan Seni ITS, vol. 7, no. 2, pp. 213-220, 2019.

[3] F. Aristiyanto, N. T. Putri, and A. H. B. Adi, "Usulan Aplikasi Metode Material Requirement Planning (MRP) dalam Perencanaan Kebutuhan Firebrick PT Semen Padang," J. Optimasi Sist. Ind., vol. 15, no. 2, pp. 217-226, 2016.

[4] Y. S. Dharmawan and P. Amelia, "MSMEs Business Process Evaluation using Business Process Management Lifecycle Approach in Gresik," in 23rd Asian Forum of Business Education (AFBE 2019), 2020, pp. 54-59.

[5] M. Rosemann,"Process Improvement Patterns," 2011. http://www.michaelrosemann.com/process-improvement-patterns/.

[6] M. A. Ramadhani, "Pemodelan Proses Bisnis Sistem Akademik Menggunakan Pendekatan Business Process Modelling Notation (Bpmn)(Studi Kasus Institut Perguruan Tinggi Xyz)," J. Informasi, VII, vol. 84, 2015.

[7] M. Rosemann and J. vom Brocke, "The six core elements of business process management," in Handbook on business process management 1, Springer, 2015, pp. 105-122.

[8] A. S. Pramudita, "Formulasi Model Bisnis Hostel di Bandung dengan Pendekatan Value Chain dan Business Model Canvas (Studi Kasus: Pinisi Backpacker)," ISEI Bus. Manag. Rev., vol. 2, no. 1, pp. 32-38, 2018.

[9] R. Yunitarini and others, "Pemodelan Proses Bisnis Akademik Teknik Informatika Universitas Trunojoyo Dengan Business Process Modelling Notation (Bpmn)," J. Simantec, vol. 5, no. 2, 2016.

[10] M. F. Hafid and A. M. S. Yusuf, "Analisis Penerapan Quality Control Circle Untuk Meminimalkan Binning Loss Pada Bagian Receiving PT. Hadji Kalla Toyota Depo Part Logistik Makassar," J. Ind. Eng. Manag., vol. 3, no. 2, pp. 1-7, 2018.

[11] E. Tinkler and P. Westlin, "Fostering Continuous Improvement and Innovation Through the Complaints Process: A case study at a global manufacturing company." 2020.

[12] S. D. Larasati, "Perbaikan Proses Bisnis Menggunakan Metode Business Process Improvement (BPI)(Studi Pada Bagian Riset Pemasaran dan Pusat Pelayanan Pelanggan PT. Petrokimia Gresik)," Universitas Brawijaya, 2017.

[13] S. Satyal, I. Weber, H. Paik, C. Di Ciccio, and J. Mendling, "Business process improvement with the AB-BPM methodology," Inf. Syst., vol. 84, pp. 283-298, 2019.

[14] H. M. J. Saputra, D. E. Marviainyda, R. A. Larasatu, M. Z. A. Addaffa, and L. H. Atrinawati, "Analisis Proses Bisnis pada Dinas Perdagangan Kota XYZ dengan Menggunakan Business Process Management Lifecycle," SPECTA J. Technol., vol. 4, no. 1, pp. 71-83, 2020.

[15] S. N. Firianti, "Analisis Proses Bisnis Pengadaan dengan Menggunakan Pendekatan Kualitatif dan Kuantitatif di PT. Telkom Akses," Institut Teknologi Sepuluh Nopember, 2018.

[16] H. S. Sadzali, N. Y. Setiawan, and I. Aknuranda, "Evaluasi dan Perbaikan Proses Bisnis Menggunakan Business Process Improvement (BPI)(Studi Kasus: Dinas Pengendalian Penduduk, Keluarga Berencana, Pemberdayaan Perempuan dan Perlindungan Anak Kabupaten Kediri)," J. Pengemb. Teknol. Inf. dan Ilmu Komput. e-ISSN, vol. 2548, p. 964, 2018.

[17] A. Widjiseno, "Pemodelan Proses Bisnis Sistem Informasi Analisis APBD Dengan Business Process Modelling Notation (BPMN)," J. Sist. Inf. Indones., vol. 3, no. 2, 2018. 